\title{
Sonographic Evaluation of Rotator Cuff Pathologies Causing Restricted Movements of Shoulder
}

\author{
Sandeep Bendale ${ }^{1}$, Shashank Vedpathak ${ }^{2}$ \\ ${ }^{1}$ Assistant Professor, Department of Radiodiagnosis, ${ }^{2}$ Associate Professor, Department of Anatomy, MIMER Medical College, \\ Talegaon Dabhade, Pune, Maharashtra, India
}

Corresponding author: Dr Shashank Vedpathak, Associate Professor, Department of Anatomy, MIMER Medical College, Talegaon Dabhade, Pune, Maharashtra, India

DOI: http://dx.doi.org/10.21276/ijcmsr.2019.4.3.61

How to cite this article: Sandeep Bendale, Shashank Vedpathak. Sonographic evaluation of rotator cuff pathologies causing restricted movements of shoulder. International Journal of Contemporary Medicine Surgery and Radiology. 2019;4(3):C276-C280.

\section{A B S T R A C T}

Introduction: Rotator cuff pathologies causing limitations of movements of shoulder is usually common in patients undergoing heavy occupational activity, elderly patients or in sports related injuries. Rotator cuff tendons in patients with restricted movements of shoulder are evaluated sonographically and the results are tabulated. Study aimed at sonographic evaluation of rotator cuff tendons in patients with restricted movements of shoulder

Material and Methods: This was a prospective observational study of 50 patients with restricted movements of shoulder undergoing ultrasonography of shoulder. Amount of restriction of movement was identified by testing the range of active, passive abduction movements of shoulder. These patients then underwent ultrasonography of shoulder with high frequency probe.

Results: We found that Supraspinatus was most commonly involved tendon in rotator cuff tears followed by infraspinatus. Partial thickness tear of supraspinatus was seen in 21 patients while full thickness tear was seen in 10 patients. In all 7 patients had tendinosis.

Conclusion: Our study found that rotator cuff tears can be diagnosed with ultrasonography in patients with restricted movements of shoulder. Supraspinatus was most commonly involved tendon amongst rotator cuff muscles and its tear was more common with increasing age, in dominant hand and slightly more common in male. So high resolution USG is cost effective, easily available and sensitive modality to diagnose rotator cuff tears.

Keywords: Full Thickness Tear, Partial Thickness Tear,Supraspinatus, Tendinosis, Ultrasound

\section{INTRODUCTION}

Shoulder joint is a multiaxial joint of ball and socket variety where the ball is formed by head of humerus and socket is formed by glenoid cavity of scapula. Movements occur around multiple axes which include flexion, extension, adduction, abduction, lateral rotation, medial rotation and circumduction.

One of most common complaints of patients with shoulder pathology are restricted movements. Clinical examination gives an idea about pathology but exact anatomical structure damaged and to what extent cannot be known.

In rotator cuff pathology supraspinatus is the most commonly involved tendon. Rupture of supraspinatus tendon is one of common causes of restricted movements of shoulder. ${ }^{1}$ The reason for frequent involvement of supraspinatus tendon is because of its anatomical location between two bones (head of humerus and acromion). It gets chronically compressed during forward flexion of shoulder joint, this leads to ischemia and later degeneration of the tendon. Rotator cuff pathologies are classified as tendinopathy, partial and full thickness rupture. $^{2}$
High resolution ultrasound is noninvasive, less expensive, non-ionizing modality with good sensitivity in detection of rotator cuff and non rotator cuff disorders. It can also reveal abnormalities that mimic rotator cuff tear clinically such as tenosynovitis, tendinosis, subacromial and subdeltoid bursitis. The rotator cuff is considered normal if it appears hyperechoeic relative to the deltoid, has a typical internal fibrillar pattern and convex superior surface. The fatty infiltration and muscle atrophy are also well depicted on sonography.

In this study, rotator cuff tendons in patients with restricted movements of shoulder are evaluated sonographically and the findings are summarised.

\section{MATERIAL AND METHODS}

This prospective, hospital based study of "Sonographic evaluation of rotator cuff pathologies causing restricted movements of shoulder " was carried out in Department of Radiodiagnosis of B. J. Medical College and Sasoon General hospitalafter obtaining proper approval from Institutional Ethical Committee. Fifty patients who attended the orthopaedic OPD for restricted movements of the shoulder joint and referred for USG were included 
in the study.Detail clinical history of patients was recorded so that data on age, sex, duration of symptoms, involvement of dominant or nondominant side, clinical presentation of symptoms, range of shoulder abduction can be tabulated. Patients were subjected to ultrasound examination. Tendons of supraspinatus, infraspinatus, teres minor and subscapularis were evaluated with high frequency probe to search for partial or full thickness tear or findings like tendinosis which may cause restricted shoulder movements. These sonographic findings were recorded.

Final clinical and radiological diagnoses were considered after adequate lab investigations, MRI, arthroscopy were performed.

\section{Selection of patient}

\section{Inclusion criteria:}

1) Patients with restricted movements of shoulder and who gave consent for undergoing ultrasound examination were included in the study.

\section{Exclusion criteria}

1) Patients with recent trauma (up to 15 days) were excluded from the study.

2) All patients who did not consent to be a part of the study.

\section{Equipments}

Ultrasound examination was done on:

GE systems - LOGIQ 3 sonography

Machine with high frequency tranducer.

\section{Patient preparation}

No specific -preparation was required before the scans.

\section{RESULTS}

About 50 patients with various shoulder pathologies were screened with sector array probe with frequencies of 5 to 12 Mhz. Both shoulders were examined in all patients. Out of

\begin{tabular}{|l|c|c|c|}
\hline \multirow{2}{*}{ Age in Yrs } & \multicolumn{2}{|c|}{ Number of patients } & \multirow{2}{*}{ Total (\%) } \\
\cline { 2 - 3 } & Male & Female & \\
\hline $41-50$ & 4 & 6 & $10(20 \%)$ \\
\hline $51-60$ & 13 & 9 & $22(44 \%)$ \\
\hline $61-70$ & 8 & 5 & $13(26 \%)$ \\
\hline$>70$ & 3 & 2 & $5(10 \%)$ \\
\hline Total & 28 & 22 & 50 \\
\hline \multicolumn{4}{|c|}{ Table-1: Age Distribution } \\
\hline
\end{tabular}

\begin{tabular}{|l|c|c|}
\hline Sex & No. of cases & Percentage \\
\hline Male & 28 & $56 \%$ \\
\hline Female & 22 & $44 \%$ \\
\hline Total & 50 & $100 \%$ \\
\hline \multicolumn{2}{|c|}{ Table-2: Gender distribution } \\
\hline
\end{tabular}

\begin{tabular}{|l|c|c|}
\hline & No of cases & Percentage \\
\hline Right & 32 & $64 \%$ \\
\hline Left & 18 & $36 \%$ \\
\hline Total & 50 & $100 \%$ \\
\hline \multicolumn{2}{|c|}{ Table-3: Dominant hand } \\
\hline
\end{tabular}

the total 50 patients, no patient showed bilateral involvement of shoulder.

Table no 1 . Shows that maximum numbers of patients were in the age group of $51-60 \mathrm{yrs}$ ( $44 \%$ of patients). The next age

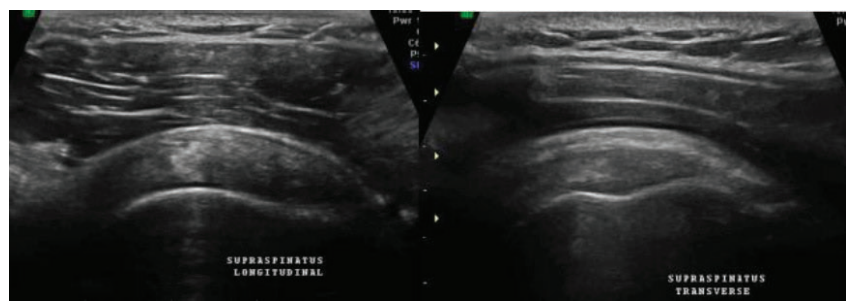

Figure-1: Supraspinatus. Transverse and longitudinal images.

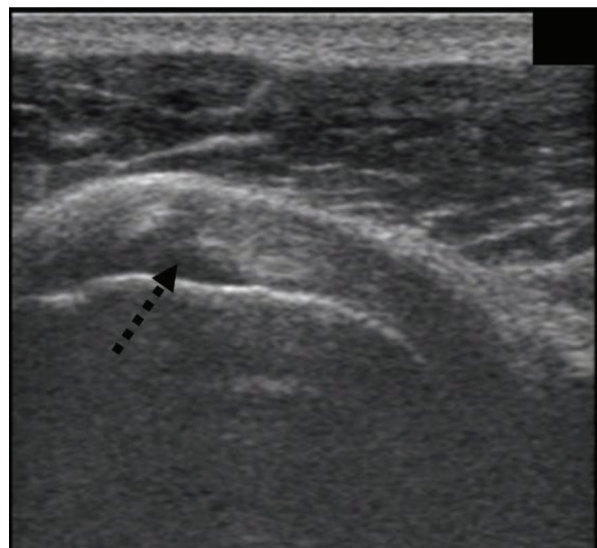

Figure-2: Articular surface partial thickness tear of supraspinatus tendon

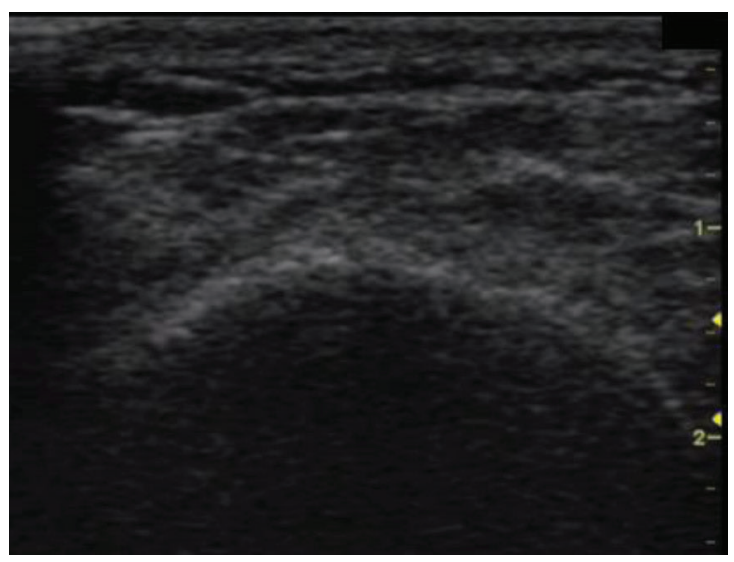

Figure-3: Full thickness tear of supraspinatus tendon with significant retraction of proximal end of tendon - deltoid resting on humeral head.

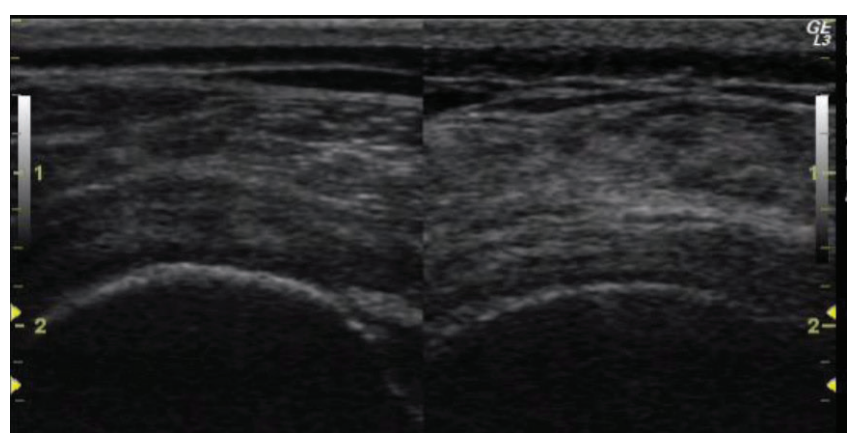

Figure-4: Supraspinatus Normal left on right tendinosis on right supraspinatus tendon side. 


\begin{tabular}{|l|c|c|}
\hline Duration & No. of cases & Percent \\
\hline$<1$ month & 2 & $4 \%$ \\
\hline 1 to 6 months & 5 & $10 \%$ \\
\hline 6 mths to 1 year & 35 & $70 \%$ \\
\hline More than 1 year & 8 & $16 \%$ \\
\hline \multicolumn{2}{|c|}{ Table-4: Duration of symptoms } \\
\hline
\end{tabular}

\begin{tabular}{|l|c|c|}
\hline Clinical symptoms & No of patients & Percent \\
\hline Restricted movements & 50 & $100 \%$ \\
\hline H/o old trauma & 10 & $20 \%$ \\
\hline Tendernesss & 40 & $80 \%$ \\
\hline \multicolumn{2}{|c|}{ Table-5: Clinical presentation of patients } \\
\hline
\end{tabular}

\begin{tabular}{|l|c|c|}
\hline Range & $\begin{array}{c}\text { No of } \\
\text { patients }\end{array}$ & Percentage \\
\hline$<45$ & 2 & $4 \%$ \\
\hline 45 to 120 degree & 18 & $36 \%$ \\
\hline $\begin{array}{l}\text { 120 degree to limited overhead } \\
\text { abduction }\end{array}$ & 30 & 60 \\
\hline \multicolumn{2}{|c|}{ Table-6: Range of abduction motion } \\
\hline
\end{tabular}

\begin{tabular}{|l|c|c|}
\hline Condition & Number of patients & Percent \\
\hline Partial thickness & 21 & $42 \%$ \\
\hline Full thickness & 10 & $20 \%$ \\
\hline Osteoarthritis AC joint & 16 & $32 \%$ \\
\hline Frozen shoulder & 11 & $22 \%$ \\
\hline Osteoarthritis GHJ & 4 & $8 \%$ \\
\hline \multicolumn{2}{|c|}{ Table-7: Incidence of no. of cases } \\
\hline
\end{tabular}

\begin{tabular}{|l|c|c|c|c|}
\hline Muscle & $\begin{array}{c}\text { Partial } \\
\text { thick } \\
\text { ness tear }\end{array}$ & $\begin{array}{c}\text { Full thick } \\
\text { ness tear }\end{array}$ & $\begin{array}{c}\text { Tendi } \\
\text { Nosis }\end{array}$ & Normal \\
\hline Supra spinatus & 21 & 10 & 5 & 14 \\
\hline Infra spinatus & 2 & 0 & 0 & 48 \\
\hline Subscapularis & 0 & 0 & 2 & 48 \\
\hline Teres Minor & 0 & 0 & 0 & 50 \\
\hline Biceps tendon & 0 & 0 & 0 & 50 \\
\hline \multicolumn{6}{|l|}{ Table-8: USG findings: Rotator cuff Tears } \\
\hline
\end{tabular}

group affected was $61-70 \mathrm{yrs}$ (with $26 \%$ of patients).

Table no. 2 shows that present study included more number of male patients, $\mathrm{n}=28(56 \%)$ as compared to females, $\mathrm{n}=22$ (44\%) with male female ratio of 1.27:1.

Table no. 3 shows that in $64 \%$ cases right hand was dominant hand while in $36 \%$ patients left hand was dominant hand. Among all patients, $70 \%$ patients were having right sided shoulder pathology while remaining 30\% patients had left sided shoulder pathology

Table no 4 shows that most common group of patients in our study was having shoulder complains since 6 months to 1 year. Though all patients in our study were of age more than 40 years, we found very few patients in other groups.

Table no. 5 shows that the most common presenting complaint was painful restricted movements of shoulder which was present in all 50 patients (100\%) followed by shoulder pain and tenderness which was present in 40 patients (80\%). Only $10 \%$ patients had history of old trauma. Table no 6 shows that in our study group, largest group was having $>120^{\circ}$ abduction possible but not full range overhead abduction. In this group cause of restriction of active movement was mainly pain and most of these patients were diagnosed to have recent rotator cuff tears and acromioclavicular joint osteoarthritis. Two patients had less than 45 degree abduction possible on both active and passive movements. These two patients were later diagnosed to have frozen shoulder. 11 patients of frozen shoulder showed significant restriction of movements ranging in less than 45 degree and 45 to 120 degree.

Table no. 7 shows that rotator cuff tear cases was commonest cause of restricted shoulder movements found in $62 \%$ patients. Among them, partial thickness tears were seen more than full thickness tears. Osteoarthritis of acromioclavicular joint was the next most common cause of restricted movements of shoulder found in $32 \%$ patients.

Table no 8 shows that supraspinatus was the most commonly involved tendon with its partial thickness tear seen in 21 patients and full thickness tear seen in 10 patients. Two partial thickness supraspinatus tears extended into infraspinatus. We found subscapularis tendinosis in 2 patients and supraspinatus tendinosis in 5 patients. We did not find involment of teres minor or bicep tendon.

\section{DISCUSSION}

The present study was undertaken to find out different causes shoulder pathology in patients of restricted movements of shoulders by ultrasonography

Patients included in our study were referred for restricted movements and shoulder pain. Detail clinical examination findings were noted. All 50 patients underwent USG of both shoulders although no patient showed bilateral involvement of shoulder.

\section{Age distribution of patients}

In our study, incidence of shoulder pathologies is seen to increase from third through fifth decade. This trend is similar to that seen in study by William D. Middleton et al. ${ }^{1}$ Young patients usually present with shoulder pain without restricted movements. Common pathologies observed in young age group are fractures, labral tears, history of recurrent dislocations, etc.

\section{Gender distribution of cases}

Males are more prone to shoulder related disorders especially if they are concerned with heavy occupational activity. Thomas D. Brandt ${ }^{2}$ conducted a retrospective and prospective evaluation of clinical usefulness of shoulder sonography in evaluation of shoulder pathologies and found male predominance in shoulder related pathologies as in our study. This finding is also consistent with William D. Middleton ${ }^{1}$ study who found 72 male patients out of 106 shoulders who were referred for shoulder USG and arthrography.

Present study shows that most patients had dominant shoulder involvement which is commonly right. So, there was significant difference in the side involved. This finding is also consistent with William D. Middleton ${ }^{1}$ study who found dominant shoulder involvement. 


\section{Duration of symptoms}

In elderly patients, degenerative diseases are more common which often are of gradual onset and gradually progressive. So the present study found $70 \%$ patients having duration of symptoms 6 months to one year. Diseases commonly seen in elderly patients are rotator cuff tears, acromioclavicular joint osteoarthritis, frozen shoulder. These observations are consistent with observations of study by Jaffrey R. Crass. ${ }^{3}$ Degenerative joint disease is not common in glenohumeral joint as that in knee and hip joint.

\section{Clinical presentation of patients}

When we examined the patient before ultrasound, we found that most patients had more than one symptom as presenting complaints. In many of the cases pain was the cause of restricted movements. In some of these patients active movements could be normally elicited during examination and all of these category patients had tenderness over shoulder.

Thomas D. Brandt ${ }^{2}$ studied patients presented with shoulder complaints with shoulder USG. Shoulder pain is commonest presenting complaint in his study and second commonest complain was restricted shoulder movements.

\section{Range of abduction motion}

Shoulder is synovial joint which allows wide range of movements. Many shoulder pathologies restrict movements of shoulder. Shoulder abduction and external rotation is usually first affected by pathologies. Free overhead abduction was considered as normal abduction movement in our study. Frozen shoulder is clinically diagnosed by gradual onset, slowly progressive restricted movements of shoulder that first affect abduction and external rotation. The disease shows typical course of exacerbation, plateau and gradual complete or incomplete remission. In our study, 11 clinically diagnosed frozen shoulder patients were examined by USG. Shoulder movements were examined both actively and passively for our study. Passive shoulder movements were comparatively wider in range than active shoulder movements. We consider that active movements are more important for patient and these only are used for categorization of patients.

\section{Incidence of number of cases}

In the present series rotator cuff pathologies constituted maximum number of patients. Jaffrey R. Crass ${ }^{3}$ did a study on 130 patients with shoulder pain and restricted movements. Commonest pathology seen was partial thickness tear in $50 \%$ patients followed by full thickness tears of rotator cuff tendons. In study of Zlatkin et $\mathrm{al}^{4}$ they found supraspinatus involvement was present in around $80 \%$ cases. While few cases showed Acromioclavicular joint degenerative change.

\section{USG findings}

Rotator Cuff Pathologies: Figure 1 shows transverse and longitudinal appearance of normal supraspinatus muscles. Normal intact fibrillar architecture is seen.

Technical considerations in diagnosis of rotator cuff tears: We used sector array probe with frequencies of 5 to $12 \mathrm{Mhz}$. Utility of such scanners may be limited by near field artefact and narrow superficial image field.

Anisotropy is an important pitfall of ultrasonography. This artefact result because of parallel arrangement of collageneous structures. This peculiar arrangement causes, echogenicity of the tendon to depend on angle of transducer relative to the tendon during tendon interrogation. Oblique insonation of tendon will result in heterogeneous appearance of tendon, which may show focal hypoechoeic areas within the tendon mimicking partial thickness tears. To avoid this anisotropy artefact we used perpendicular insonation technique. We scanned tendons perpendicular to their fiber arrangement. While scanning over round surface of proximal humerus, we found that tendon at the center of image was hyperechoeic. Obvious focal defect, discontinuity, focal hypoechoeic area was searched in this central hyperechoeic portion. Side portions were often less well seen and were hypoechoeic. Evaluation of these side portions was performed by repositioning the probe over these portions so that tendon portion to evaluate should always be in center of image.

Before diagnosing a rotator cuff tear it is necessary to confirm that the focal hypoechoeic defect is persisting in other plane also. We found 21 partial thickness tears of supraspinatus by USG. Anisotropy and inexperienced radiologist may misdiagnose rotator cuff tears.

Partial thickness tears of Supraspinatus: Figure 2 shows, there is a small hypoechoeic area along the inferior portion of supraspinatus tendon with loss of integrity of fibrils - this suggests Articular surface partial thickness tear.

Supraspinatus was most commonly involved rotator cuff tendon to undergo degenerative tears. Partial thickness tears are more common than full thickness tears. Two partial thickness supraspinatus tears were also seen extending into infraspinatus. No independent infraspinatus or any other rotator cuff tendon tear was noted in present study. Criteria used to diagnose partial thickness supraspinatus tear was focal hypoechoeic defect reaching upto either bursal or articular surface of tendon. Focal hypoechoeic areas that do not reach articular surface or bursal surface of tendon are not categorized as tears. Soble $\mathrm{MG}^{5}$ described the major sonographic diagnostic criteria for diagnosing rotator cuff tear as a well defined discontinuity usually visible as a hypoechoeic focus in the cuff, non-visualization of the cuff and an echogenic focus within the cuff. In their study, Seventy five patients underwent both sonography and arthrography and they found ultrasound examinations enabled detection of $92 \%$ rotator cuff tears (24 of 26), with a specificity of $84 \%$ and a negative predictive value of $95 \%$. Vlychou $\mathrm{M}$ et $\mathrm{al}^{6}$ showed in his study that USG imaging can be considered almost equally effective in deteccting partial tears of the rotator cuff compared to the MRI, particularly located in the area of the supraspinaus tendon.

Full thickness tears of Supraspinatus: There is full thickness tear of supraspinatus tendon. It is seen extending upto both superior and inferior surfaces. There is also significant retraction of proximal end of tendon so that the deltoid muscle is now resting on humeral head (figure-3).

Full thickness tear of supraspinatus was seen in 10 patients in our study. Full thickness tear is well identified in USG as loss of normal convexity of supraspinatus tendon. Discontinuity of tendon fibers is also noted from the articular surface to 
the bursal surface. If the discontinuity is not seen reaching both articular and bursal surfaces of supraspinatus then it is partial thickness tear. Complete tear of supraspinatus means complete antero-posterior tendon bulk involvement. Kumugai, H. Ito and Kubo A. ${ }^{7}$ considered full thickness anechoic areas to be specific findings of complete tears.

Thomas D. Brandt $(1989)^{2}$ conducted a retrospective and prospective evaluation of clinical usefulness of shoulder sonography. Complete ruptures are further classified by them as (a) pure transverse tears, (b) pure vertical or longitudinal tears, (c) tears with retraction of tendon edges, (d) massive avulsion of the cuff (global tear).By using a comparison of sonography with surgery, using this study's criteria, Brandt demonstrated a sensitivity of $57 \%$ and a specificity $76 \%$ in detection of full thickness tears. Van Mopples $\mathrm{FI}^{8}$ found that sensitivity of sonography in detecting partial and total rotator cuff tears $86 \%$, the specificity $91 \%$. We also noted that supraspinatus was the most commonly involved tendon. Rotator cuff tendons supraspinatus and infraspinatus insert on greater tuberosity posteriorly. Their tendons are continuous near insertion to form rotator cuff to cover humeral head. We could not find any case of tear of only infraspinatus or any other rotator cuff tendon.

Subscapularis tendon tear was not found in our study.

Tendinosis: Figure-4 shows, right supraspinatus tendon is bulky and isrelatively hypoechoeic to normal left supraspinatus tendon - this suggests right supraspinatus tendinosis.

Two patients were noted to have tendinosis of subscapularis. We used bicipital groove as an anatomical landmark to differentiate subscapularis tendon from supraspinatus tendon. Subscapularis lies medial to this bicipital groove. Supraspinatus tendinosis was diagnosed by USG in 5 patients. Sonographically, tendinosis appears as focal or diffuse areas of decreased echogenicity and tendon enlargement.

Walz $\mathrm{DM}^{9}$, in his study of 548 patients noted that this normal age related degeneration is probably accelerated with increased stress or decreased resistance of the tendon by heavy occupational activity and sports related injuries. We could see that in our study most of the patients of tendinosis were elderly with age more than 55 years and were engaged in heavy occupational activity. Nathalie J. Bureau $^{10}$ sonographically examined both shoulders in small sample of patients with a clinical diagnosis of subacromial impingement. He described tendinosis as focal thickening of tendon and further added that subacromial impingement is associated with encroachment of the soft tissues between the acromion and grater tuberosity and may result from intrinsic soft tissue abnormalities such as tendinosis with thickening of tendon. We could not find significant association between tendinosis and impingement.

\section{CONCLUSION}

Our study has shown that with proper technique and experienced hands ultrasonography is a quick, cheaper and easily available method to diagnose various types of rotator cuff tears in patients with restricted movements of shoulder. Our study has found that partial thickness supraspinatus tears were most common followed by full thickness tears and tendinosis.

Rotator cuff pathologies are seen more commonly in the elderly, in dominant hand and are slightly more common in males than females.

\section{REFERENCES}

1. William D. Middleton, Gerald Eldstein, William R.Remus, G. Leland Melson, William G. Totty, William A. Murphy. Sonographic Detection of rotator cuff tears. AJR 1985; 144(2):349-353.

2. Brandt TD, Cardone BW, Grant TH, et al, rotator cuff sonography: reassessment radiology. 1989; 173(2): 323327.

3. Crass JR. USG of the Rotator Cuff Radiographics. 1985; 5(5):941-953.

4. Zlatkin MB. Rotator cuff tears, diagnostic performance of MRI. Radiology 1989; 172(3): 223-229.

5. Soble MG, Kaye AD and Guay RC. Rotator cuff Tear clinical experience with sonographic detection. Radiology. 1989; 173(2):319-321.

6. Vlychou M, Dailiana Z, Fotiadou A, Papanagitou M, Fezoulidis IV, Malizos K Symptomatic Partial Rotator Cuff Tears: Diagnostic Performance of Ultrasound and Magnetic Resonance Imaging with Surgical Correlation. Acta Radiol. 2009; 50(1): 101-105.

7. Kumagai H Ito and Kubo A. Sonographic findings of rotator cuff tears: correlation with MR imaging Nippon Igaku Hoshsen Gakkai Zasshi 1994; 54(6): 459-464.

8. Floris I van Mopes, Onmo Veldkampb, Jan Roordab. Role of ultrasonography in evaluation of painful shoulder, Eur Jr of Radiology 1995; 19(1):142-146.

9. Walz DM Miller TT, Chen S, Hofman J. MR imaging of delamination tears of the rotator cuff tendons. Skeletal Radiol. 2007: 36(5): 411-416.

10. Nathalie J. Bureau, Marc Beauchamp. Etienne Cardinal, Paul Brassard Dynamic Sonography Evaluation of Shoulder Impingement Syndrome. AJR 2006: 187(3): 216-220.

\section{Source of Support: Nil; Conflict of Interest: None}

Submitted: 23-07-2019; Accepted: 20-09-2019; Published online: 25-09-2019 